\title{
Cytological analysis of a spontaneous translocation heterozygote mosaic in Chorthippus binotatus (Orthoptera, Acrididae)
}

\author{
J. P. M. Camacho and J. Cabrero
}

Departamento de Genética, Facultad de Ciencias, Universidad de Granada, 18071 Granada, Spain.

An interchange heterozygote mosaic male of the grasshopper Chorthippus binotatus was found among the 37 individuals analysed from a natural population. The mosaicism of this individual led us to deduce that the $L_{1}-L_{2}$ interchange had place when the testis primordium consisted of about $\mathbf{1 0}$ cells. The break points were located at the boundary between the paracentromeric $C$-bands and the euchromatin of the short arms of both the $L_{1}$ and the $L_{2}$ chromosomes. The $L_{1}-L_{2}$ interchange did not affect the chiasma formation properties of the $L_{1}$ and $L_{2}$ bivalents, with the single exception of the $L_{2}$ long arm. A significant deficiency of alternate orientations was detected with respect to a randomly orientation of the four centromeres in the multiples. On the other hand, the centromere orientation in the $L_{1}-L_{2}$ multiples was independent on the chiasma distribution in their different regions. A significantly higher frequency of spermatic macronuclei was observed in the follicles carrying the $L_{1}-L_{2}$ interchange with respect to those lacking it, but their frequency (1.5 per cent) was insignificant compared with that of the adjacent orientations which are, undoubtedly, the main source of infertility in this male.

\section{INTRODUCTION}

Meiotic behaviour of the multiple chromosome configurations in heterozygous individuals for reciprocal translocations rests on three key facts: (a) The pairing between all chromosomes with partial homology, (b) Chiasma formation in the different regions of the multiple, and (c) Centromere orientation at anaphase $\mathrm{I}$. The application of the C-banding technique lets, in many cases, the precise identification of each of the four centromeres in an interchange multiple and, consequently, the distinction of the different types of centromere orientation (Arana et al., 1980, 1982; Gosálvez et al., 1982; Cabrero and Camacho, 1985). An additional fact may be of great aid to analyse the meiotic behaviour of a translocation, namely the mosaicism of the carrier individual which allows the comparison of cells with and without the translocation all possessing the same genotype, by which any differences observed can be unambiguously attributed to the translocation itself.

This paper analyses cytologically one male of the grasshopper Chorthippus binotatus which was heterozygote mosaic for a reciprocal translocation between the $L_{1}$ and the $L_{2}$ chromosomes.

\section{MATERIALS AND METHODS}

Eighteen males and 19 females were caught at the Dornajo (Sierra Nevada, Granada, Spain) during the summer of 1983. The methods employed for the cytological analysis of this material were those described in Cabrero and Camacho (1985).

\section{RESULTS}

The interchange observed in the mutant male involved the great majority of the short arms of these chromosomes so that both interchanged segments showed a similar size, by which it was impossible to distinguish between them in the multiple configurations. Given the mosaicism of this male, we studied individually the 78 testis follicles it possessed and found 54 normal and 6 wih the $L_{1}-L_{2}$ interchange (in 18 others there were non analysable cells). In all, the interchange was present in 10 per cent of the testis follicles of this male. Although size and morphology of the chromosomes involved in the interchange ( $L_{1}$ and $L_{2}$ ) were similar, we could distinguish them by the different size of their paracentromeric $C$-band, that of the $L_{2}$ being larger than that of the $L_{1}$ 
(figure 1). The existence of only two sizes (large for $L_{2}$ and small for $L_{1}$ ) of paracentromeric $C$ bands in the multiples and the absence of $C$-bands with an intermediate size demonstrate that the break points were sited at the boundary between these $C$-bands and the euchromatin of the short arm in both the $L_{1}$ and the $L_{2}$ chromosomes, and excludes the possibility that it was a whole arm translocation.

Fig. 1 and table 1 show chiasma formation in the multiple besides the different multiple configurations and orientations. The multiple shows almost always a ring configuration resulting of chiasma formation in the four regions. A series of chiasma comparisons using the methods described in Cabrero and Camacho (1985) demonstrated that (a) there was not significant difference between diplotene and metaphase I cells for chiasma frequency in the multiple and the remainder bivalents, (b) There was neither inter- nor intrachromosomal interference, (c) normal and mutant cells from the mosaic male did not differ significantly for chiasma frequency in the multiple (versus $L_{1}+L_{2}$ ), in the remainder bivalents and in total cell.

If multiple centromere orientation were at random, we would expect the alternate, adjacent-1 and adjacent- 2 orientations in a $2: 1: 1$ proportions, respectively. A $X^{2}$ test demonstrated the existence of a significant deficiency of alternate orientations $\left(X_{(2)}^{2}=28.6, P<0.001\right)$ and hence that the four centromeres in the multiple do not orientate randomly. On the other hand, centromere orientations do not seem to depend on the chiasma distribution in the multiple because multiples with the same chiasma distribution (or instance, 1I, 1II, 1III, 2IV) may show adjacent-1, adjacent- 2 or alternate orientation (see table 1). The frequency of adjacent

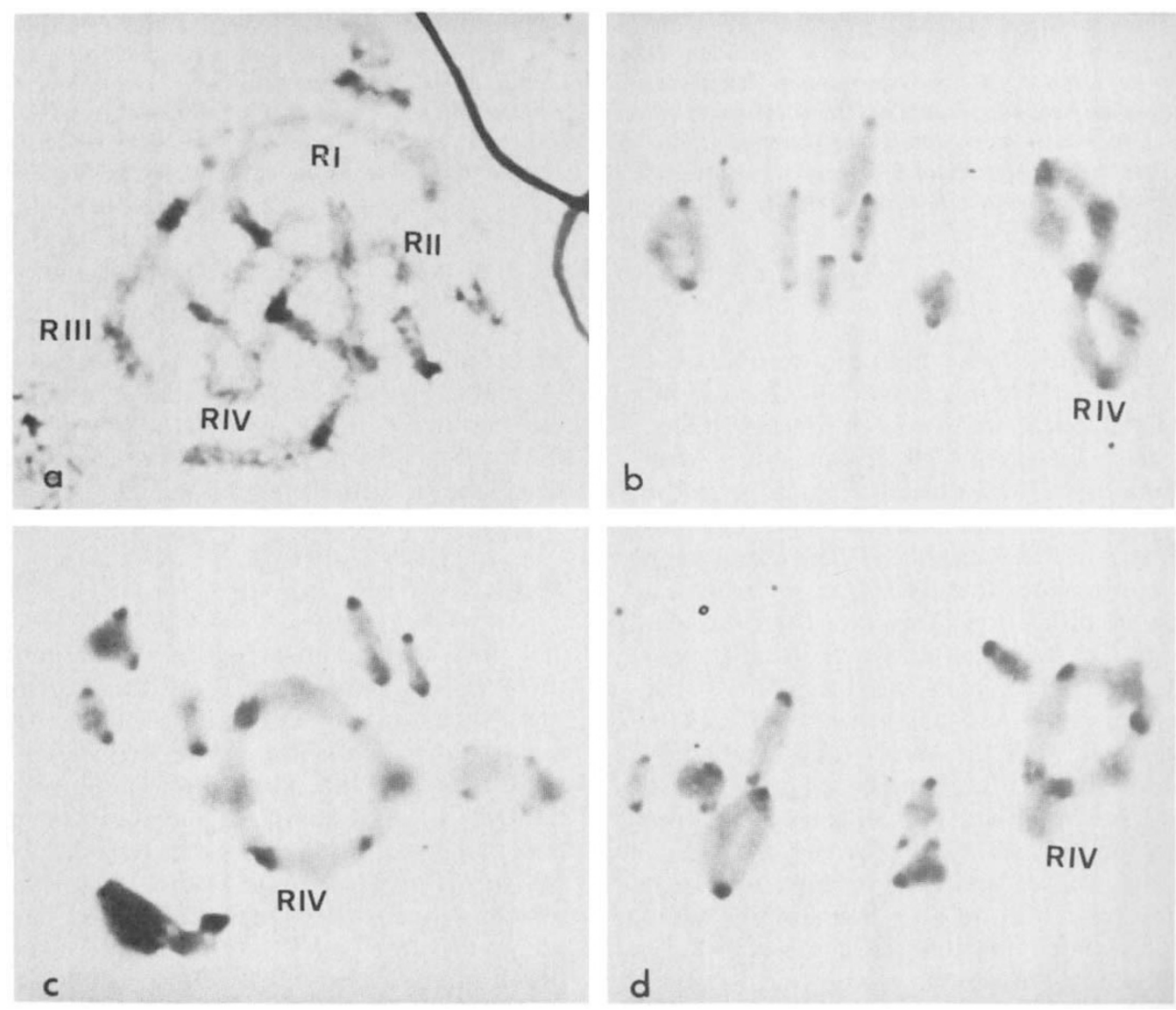

Figure $1 L_{1}-L_{2}$ interchange in the mosaic male of Chorthippus binotatus. (a) Pachytene cell showing the interchange pairing cross and the four different regions. (b) Metaphase I cell showing alternate multiple orientation and the presence of one chiasma in each of the four regions. (c) Metaphase I cell showing adjacent-1 multiple orientation, and a 1I, 1II, 1III, 2IV chiasma distribution. (d) Metaphase I cell showing adjacent-2 orientation and a 2I, III, 1III, IIV chiasma distribution. 
Table 1 Chiasma frequency, configurations and orientation of multiples in diplotene and metaphase I cells of Ch.binotatus. C: chain, R: ring configuration

\begin{tabular}{|c|c|c|c|c|c|c|c|}
\hline \multirow[b]{2}{*}{ Stage } & \multicolumn{4}{|c|}{$\begin{array}{c}\text { Number of chiasmata } \\
\text { in Region }\end{array}$} & \multirow{2}{*}{$\begin{array}{l}\text { Multiple } \\
\text { configuration }\end{array}$} & \multirow[b]{2}{*}{ Orientation } & \multirow{2}{*}{$\begin{array}{l}\text { Number } \\
\text { of cells }\end{array}$} \\
\hline & I & II & III & IV & & & \\
\hline \multirow[t]{5}{*}{ Diplotene } & 1 & 1 & 0 & 1 & IV-C & & 1 \\
\hline & 1 & 1 & 1 & 1 & IV-R & & 11 \\
\hline & 1 & 1 & 1 & 2 & IV-R & & 5 \\
\hline & 2 & 1 & 1 & 2 & IV-R & & 2 \\
\hline & & & & & & Total & $\overline{19}$ \\
\hline \multirow[t]{9}{*}{ Metaphase I } & 1 & 1 & 1 & 1 & IV-R & Alternate & 8 \\
\hline & 1 & 1 & 1 & 2 & IV-R & Alternate & 4 \\
\hline & 1 & 1 & 1 & 1 & IV-R & Adjacent-1 & 22 \\
\hline & 1 & 1 & 1 & 2 & IV-R & Adjacent-1 & 6 \\
\hline & 2 & 1 & 1 & 1 & IV-R & Adjacent-1 & 1 \\
\hline & 1 & 1 & 1 & 1 & IV-R & Adjacent-2 & 19 \\
\hline & 1 & 1 & 1 & 2 & IV-R & Adjacent-2 & 7 \\
\hline & 2 & 1 & 1 & 1 & IV-R & Adjacent-2 & 1 \\
\hline & & & & & & Total & $\overline{68}$ \\
\hline
\end{tabular}

orientations $(82 \cdot 35$ per cent $)$ corresponds to that of unbalanced spermatozoa formed in the follicles carrying the $L_{1}-L_{2}$ interchange.

An analysis of spermatic nucleı (1015 from mutant and 1003 from normal follicles) and spermatids (1008 from mutant and 1004 from normal follicles) demonstrated that mutant follicles form significantly more macronuclei ( 1.48 per cent) than normal ones $(0.30$ per cent $)\left(X_{(1)}^{2}=6.65, P: 0.01-\right.$ $0 \cdot 001)$, but they do not differ for the frequency of macrospermatids $(0.79$ per cent in mutant and 0.40 per cent in normal follicles) $\left(X_{(1)}^{2}=0.79, P: 0.3-\right.$ $0 \cdot 5)$.

\section{DISCUSSION}

The $L_{1}-L_{2}$ interchange detected in the mosaic male of Chorthippus binotatus analysed in this report originated de novo during the embryonic development of its testes. Having in mind that the interchange was present in 10 per cent of the follicles analysed and, on the other hand, that it originated presumably in a single embryonic cell, it may be estimated that the mutation took place when the embryonic primordium for the testes consisted of about 10 cells. Following the same reasoning it may be estimated that the $L_{1}-S_{8}$ interchange reported in a mosaic male of Stauroderus scalaris by Cabrero and Camacho (1985), which was present in 30 per cent of the follicles, arisen when the embryonic primordium for the testes in this individual consisted of about three cells.
The interchange break points were presumably sited at the boundary between the paracentromeric $C$-band and the euchromatin of the short arms of both the $L_{1}$ and the $L_{2}$ chromosomes. Thus, in fact, this interchange lacks interstitial segments since they consist of the half of each paracentromeric $C$-band in the $L_{1}$ and $L_{2}$ which, as can be presumed, do not form chiasmata.

Besides the infertility derived from predominance of adjacent orientations of the multiple, the follicles carrying the $L_{1}-L_{2}$ interchange in the mosaic male of $C h$. binotatus showed a rate of abnormal spermatic macronuclei significantly higher than that observed in normal follicles. Anyway, the loss in fertility due to the macronuclei ( 1.5 per cent) is insignificant compared to that caused by the adjacent orientations of the multiple $(82.35$ per cent $)$.

The $L_{1}-L_{2}$ interchange of $C h$. binotatus showed many favourable characteristics for a disjunctional orientation, specifically: (a) the morphology of the $L_{1}$ and $L_{2}$ chromosomes was not modified, (b) a multiple of four was always formed, (c) the multiple was very symmetric, (d) the four centromeres were located equidistantly, and (e) there were not interstitial segments. However, there was a significant deficiency of alternate orientations. That seems to be a general characteristic of the interchanges in grasshoppers since it has also been observed in Gomphocerus sibiricus for an interchange with similar characteristics to that of Ch.binotatus (Gosálvez et al., 1982). Such a non-disjunctional behaviour of the interchange 
multiples could be one of the most important causes for the absence of interchange polymorphisms in natural populations of grasshoppers.

\section{REFERENCES}

ARANA, P., SANTOS, J. L. AND GIRALDEZ, R. 1980. Chiasma interference and centromere co-orientation in a spontaneous translocation heterozygote of Euchorthippus pulvinatus gallicus (Acrididae: Orthoptera). Chromosoma, 78, $327-340$.
ARANA, P., SANTOS, J. L., HENRIQUES-GIL, N. AND GIRALDEZ, R. 1982. Centromere co-orientation in a spontaneous translocation heterozygote of Euchorthippus pulvinatus gallicus (Acrididae, Orthoptera). Genetica, 58, 81-84.

CABRERO, J. AND CAMACHO, J. P. M. 1985. A spontaneous interchange heterozygote mosaic in the grasshopper Stauroderus scalaris: interchromosomal chiasma effects. Heredity, 54, 235-243.

GOSALVEZ, J., LOPEZ-FERNANDEZ, C. AND GARCIALAFUENTE, R. 1982. A spontaneous translocation heterozygote involving centromere regions in Gomphocerus sibiricus (L.) (Orthoptera: Acrididae). Chromosoma, 86, 49-57. 